\title{
Transgenic Nicotiana occidentalis Plants Expressing the 50-kDa Protein of Apple chlorotic leaf spot virus Display Increased Susceptibility to Homologous Virus, but Strong Resistance to Grapevine berry inner necrosis virus
}

\author{
N. Yoshikawa, S. Gotoh, M. Umezawa, N. Satoh, H. Satoh, T. Takahashi, T. Ito, and K. Yoshida
}

First to sixth authors: Faculty of Agriculture, Iwate University, Ueda 3-18-8, Morioka 020-8550, Japan; seventh author: Department of Citriculture, National Institute of Fruit Tree Science, Kuchinotsu Otsu 870, Minamitakakigun 859-2501, Japan; and eighth author: Apple Research Center, National Institute of Fruit Tree Science, Nabeyasiki 92, Shimokuriyagawa, Morioka 020-0123, Japan. Accepted for publication 5 December 1999.

\begin{abstract}
Yoshikawa, N., Gotoh, S., Umezawa, M., Satoh, N., Satoh, H., Takahashi, T., Ito, T., and Yoshida, K. 2000. Transgenic Nicotiana occidentalis plants expressing the 50-kDa protein of Apple chlorotic leaf spot virus display increased susceptibility to homologous virus, but strong resistance to Grapevine berry inner necrosis virus. Phytopathology 90:311-316.

The 50-kDa protein (P50) encoded by the open reading frame 2 of Apple chlorotic leaf spot virus (ACLSV), a putative movement protein, was expressed in transgenic Nicotiana occidentalis plants. P50 in transgenic plants was mainly detected in a modified form in the cell wall fraction, similar to that in infected leaves. The P50-expressing plants (P50 plants) complemented the systemic spread of the P50-defective mutants of an infectious cDNA clone of ACLSV (pCLSF), indicating that P50 in transgenic plants was functional. Severity of symptoms was greatly enhanced and

lated with pCLSF or ACLSV compared with that in nontransgenic control plants (NT plants). Conversely, transgenic plants expressing the coat protein of ACLSV (CP plants) showed a significant delay in symptom development and a reduction of virus accumulation. However, most P50 plants inoculated with Grapevine berry inner necrosis virus (GINV), another species of the genus Trichovirus, neither developed obvious symptoms nor supported virus accumulation in inoculated or upper leaves. In contrast, systemic symptoms developed and virus accumulated equally in NT and CP plants inoculated with GINV. After inoculation with Apple stem grooving virus or Apple stem pitting virus, there was no difference in symptom development and virus accumulation among P50, CP, and NT plants. Our results indicate that transgenic plants expressing a functional P50 were more susceptible to homologous virus and, on the contrary, showed strong resistance to the heterologous virus GINV.
\end{abstract} accumulation of virus in upper leaves was increased in P50 plants inocu-
Apple chlorotic leaf spot virus (ACLSV) has flexuous filamentous particles, approximately 600 to $700 \mathrm{~nm}$ in length, and is the type species of the genus Trichovirus. The virus contains a polyadenylated, plus-sense, single-stranded RNA with a molecular mass of $2.48 \times 10^{6} \mathrm{Da}$ and a single coat protein $(\mathrm{CP})$ of $22 \mathrm{kDa}(35)$. The ACLSV genomes of three isolates, P863 from plum, P-205 from apple, and Ball from cherry, have been completely sequenced $(10,11,24)$. The P-205 genome consists of 7,552 nucleotides (nt) excluding the poly(A) tail and contains three open reading frames (ORF) that encode a $216-\mathrm{kDa}$ protein involved in replication (ORF1), a 50-kDa protein (ORF2), and a 21-kDa CP (ORF3) (24). The 50-kDa protein (P50) is thought to be a movement protein (MP) based on its amino acid sequence similarity with MPs of other plant viruses and its localization on plasmodesmata in infected tissues $(10,17,24,25,33)$.

Plant viruses move from cell to cell in the plant through plasmodesmata, which connect the cytoplasm between neighboring cells $(4,20)$. The MPs of plant viruses are localized to plasmodesmata in infected and transgenic plant cells $(2,7,8,19,29)$, induce a significant increase in the plasmodesmatal size exclusion limit (31), and also bind single-stranded RNA (5). This allows the viral genome to migrate from cell to cell (9). The MPs expressed in transgenic plants are known to be functional and can complement the cell-to-

Corresponding author: N. Yoshikawa; E-mail address: yoshikawa@iwate-u.ac.jp

Publication no. P-2000-0127-01R

(C) 2000 The American Phytopathological Society cell movement of MP-defective viral mutants $(12,14)$. Recently, transgenic plants expressing nonfunctional MP were reported to be resistant to heterologous viruses in addition to homologous virus $(1,3,6,21,27)$. This phenomenon is called MP-derived resistance (27). For example, transgenic plants expressing a defective MP of Tobacco mosaic virus (TMV) are resistant to TMV and also to viruses of other taxa, i.e., Tobacco rattle virus, Tobacco ringspot virus, Alfalfa mosaic virus, Cucumber mosaic virus, and Peanut streak virus, in which there are significant delays in the time of symptom appearance and a reduction of virus accumulation (6). Conversely, transgenic plants expressing a functional TMV-MP accelerated symptom development, enhanced the severity of symptoms, and increased the accumulation of the viruses (6). It is also reported that transgenic plants expressing a mutated form of triplegene-block (TGB) proteins of Potato virus $X(\mathrm{PVX})$ and White clover mosaic virus have broad-spectrum resistance against TGBcontaining potex- and carlaviruses, but not to Potato virus $Y$ (PVY) (3). The resistance is thought to be due to interference between the modified MP and that of the challenging virus. In addition, the transgenic plants expressing a functional $24-\mathrm{kDa}$ protein $(\mathrm{P} 24)$ encoded by PVX-TGB are resistant to TMV and $\mathrm{Ob}$ tobamoviruses, but not to PVY (1).

In the current study, we constructed transgenic Nicotiana occidentalis plants expressing a functional P50 of ACLSV and investigated the responses of the transgenic plants inoculated with homologous virus, Grapevine berry inner necrosis virus (GINV), and taxonomically different Apple stem grooving virus (ASGV) and Apple stem pitting virus (ASPV). 


\section{MATERIALS AND METHODS}

Construction of plasmids and plant transformation. Two plasmids, pBE2113-50K and pBE2113-CP, that express the full-length ORF2 protein (P50) and a CP of ACLSV, respectively, were constructed as follows. The ORF2 region was amplified by polymerase chain reaction (PCR) using EX Taq DNA polymerase (Takara Shyuzo Co., Otsu, Japan), pBCLS38 (24) as template, and two primers: 50K-Bam(+) (5'AGAGAGGATCCATGATGATAAGGGGT3', corresponding to nt positions 5,727 to 5,741 [underlined] of the ACLSV [P-205] genome [24] and containing a BamHI site) and 5'CTCTCTCATGGGTTCAAGAG3' (complementary to nt positions 7,456 to 7,475). The PCR product was digested with BamHI and SacI, and the resulting DNA fragment (nt positions 5,727 to 7,204 of the ACLSV genome) was ligated to plant expression vector pBE2113GUS (22), which was cut with the same restriction enzymes, resulting in the elimination of the GUS gene. The resulting plasmid was called pBE2113-50K.

The CP region was amplified as above using two primers: CLS$\mathrm{CP}(+)$ Bam (5'AGAGAGGATCCATGGCGGCAGTGCTG3', corresponding to nt positions 6,784 to 6,798 [underlined] of the genome and containing a BamHI site) and CLS-CP(-)Sma (5'AGAGACCCGGGTTCAAGAGTTTG3', complementary to nt positions 7,452 to 7,466 [underlined] of the genome and containing a SmaI site). The amplified DNA fragment was digested with BamHI and SmaI and ligated to pBE2113-GUS, which was previously digested with SacI; filled in by T4 DNA polymerase; and then deprived of the GUS gene by digestion with BamHI. The plasmid is denoted as

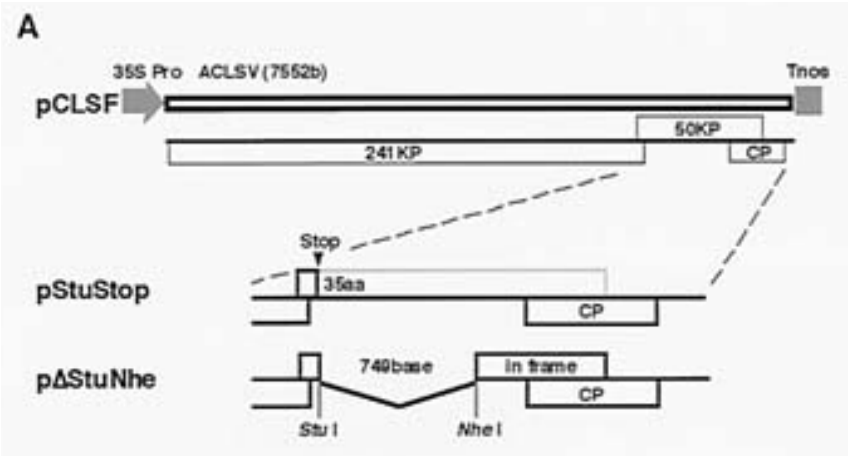

B

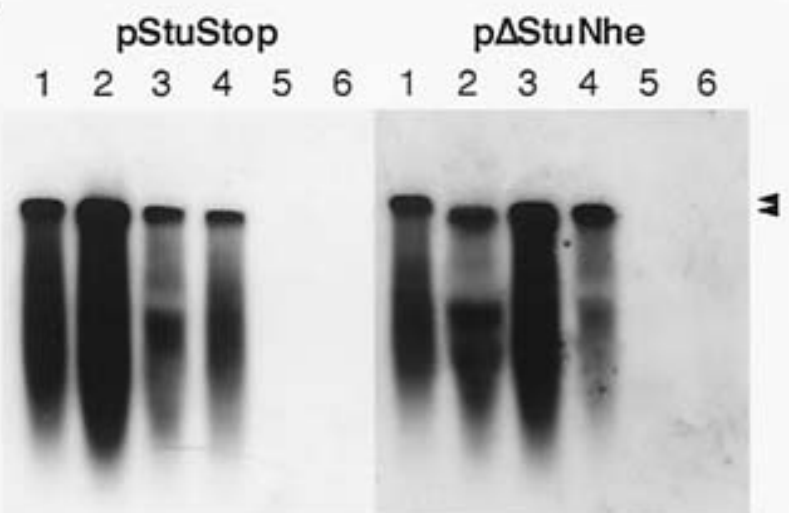

Fig. 1. A, Genetic maps of Apple chlorotic leaf spot virus (ACLSV) infectious cDNA clone pCLSF and two 50-kDa protein (P50)-defective mutants (pStuStop and $\mathrm{p} \Delta$ StuNhe). B, Northern blot analyses of total RNA from upper leaves of transgenic Nicotiana occidentalis plants expressing the ACLSV P50 and later inoculated with a P50-defective mutant. Lane 1, Nontransgenic (NT) plants inoculated with pCLSF; lanes 2, 3, and 4, P50 plant inoculated with a defective mutant, lines d-5, d-12, and d-13, respectively; lane 5, NT plants inoculated with a defective mutant; and lane 6, uninoculated NT plants. Arrowheads show the positions of the genomic bands derived from pCLSF (upper) and $\mathrm{p} \Delta \mathrm{StuNhe}$ (lower).
pBE2113-CP. The plasmids pBE2113-50K and pBE2113-CP were transformed into Escherichia coli (JM109) and transferred to Agrobacterium tumefaciens strain LBA 4404 by electroporation.

Leaves of $N$. occidentalis '37B' were cut into pieces $\left(0.7\right.$ to $\left.1.5 \mathrm{~mm}^{2}\right)$ and inoculated with the transformed A. tumefaciens, as described by Horsch et al. (13). Transformants were selected for resistance to kanamycin $(100 \mu \mathrm{g} / \mathrm{ml})$. Resistant calli were induced to regenerate shoots and roots, and regenerated plants were transferred to soil and placed in a growth chamber. These transgenic plants showed no observable phenotypic response to the insertion of the genes. Each transgenic plant gave fertile progeny by self-fertilization, and $\mathrm{R}_{1}$ seedlings were used in the following experiments.

Immunoblot analyses. Immunoblot analyses of P50 and CP in transgenic $R_{1}$ seedlings were conducted using antisera against P50 expressed in E. coli and virus particles, as described previously (25). Total proteins were extracted from leaves $(0.1 \mathrm{~g})(25)$, electrophoresed in sodium dodecyl sulfate-polyacrylamide gel, and analyzed by immunoblotting.

The leaves at three different developmental stages, i.e., young (twelfth leaf, YL), developing (ninth leaf, DL), and matured (fifth leaf, ML) leaves, were collected from a P50-transgenic plant at the thirteen-true-leaf stage. Subcellular extracts (CW, CW-T, P-30, and S-30) were prepared from YL, DL, and ML as described by Kormelink et al. (18). Total proteins and subcellular proteins were analyzed by immunoblotting using a P50 antiserum.

Infectious cDNA clone and deletion mutants. An infectious cDNA clone of ACLSV (pCLSF) (26) and two P50-defective mutants (pStuStop and $\mathrm{p} \Delta$ StuNhe) (Fig. 1) were constructed as follows. A primer, AC5830StuStop(+) (5'CTTGAGACCTTATGATTCATTGG3', corresponding to nt positions 5,830 to 5,852 of the P-205 genome), was designed to change TCT $(5,832$ to 5,834$)$ to the TGA stop codon (underlined). The ORF2 region was amplified using primer pair AC5830StuStop(+) and 5'TCACACACTTGGCGGAAG3' (complementary to nt positions 7,083 to 7,100 of the P-205 genome) by Deep Vent DNA polymerase (New England Biolabs Inc., Beverly, MA), and the amplified DNA was digested with NheI. A 750-bp fragment was recovered and then ligated to pCLSF, eliminating the fragment between the StuI (nt 5,830) and NheI (nt 6,580) sites. The resulting mutant was designated pStuStop.

The plasmid pCLSF was digested with NheI and filled in by T4 DNA polymerase. The plasmid was then digested with StuI, removing a 750-nt fragment between the StuI and NheI sites, and blunt-end ligated. The mutant was denoted $\mathrm{p} \Delta$ StuStop. The plasmids were transformed into $E$. coli and purified from large-scale cultures by $\mathrm{CsCl}$ equilibrium centrifugation (23).

A

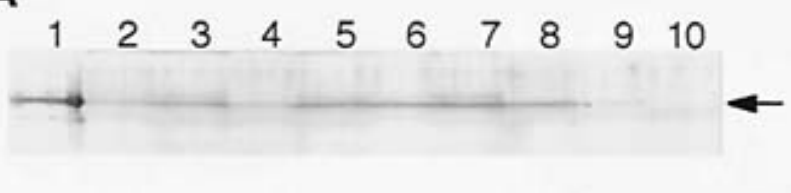

B

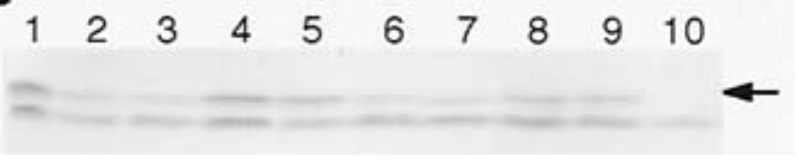

Fig. 2. Immunoblot analyses of transgenic Nicotiana occidentalis plants expressing Apple chlorotic leaf spot virus (ACLSV) A, 50-kDa protein (P50) or B, coat protein (CP). A, Lane 1, P50 expressed in Escherichia coli; lanes 2 to 9, leaf samples from kanamycin-resistant $\mathrm{R}_{\mathrm{l}}$ seedlings of line d-12; lane 10, a leaf sample from a nontransgenic (NT) N. occidentalis plant. B, Lane 1, A leaf sample from an ACLSV-infected plant; lanes 2 to 9, leaf samples from kanamycinresistant $\mathrm{R}_{1}$ seedlings of line $\mathrm{CP}-4$; and lane 10 , a leaf sample from a NT $N$. occidentalis plant. Arrows indicate the positions of A, P50 and B, CP. 
Inoculation of ACLSV infectious cDNA clone and the P50defective mutants by particle bombardment. Inoculation of the cDNA clones by particle bombardment was conducted with the Biolistic PDS-1000 Particle Delivery System (Nippon Bio-Rad Laboratories, Tokyo) as described previously (26).

Transgenic $N$. occidentalis plant $\mathrm{R}_{1}$ seeds were sowed in soil in a cell tray (5-cm square, four wells). The seedlings were grown until the plants had four to five expanded true leaves. $R_{1}$ plants were assayed for expression of P50 or CP by immunoblotting as described above and inoculated by bombardment at a target distance of 6 to $7 \mathrm{~cm}$ as above. The seedlings were planted in pots and grown in a growth chamber for symptom observation. Leaves from inoculated plants were also analyzed by northern blot hybridization as described later.

Mechanical inoculation of viruses. Viruses used in this study were ACLSV (P-205) (24), GINV (32), ASGV (P-209) (34), and ASPV (B-39) (16). The first three viruses were propagated in Chenopodium quinoa, and ASPV was propagated in N. occidentalis.

Inocula were prepared as follows. ACLSV- or ASGV-infected C. quinoa plants $(30 \mathrm{~g})$ were homogenized in $100 \mathrm{ml}$ of $0.01 \mathrm{M}$ Tris- $\mathrm{HCl}(\mathrm{pH} 7.2)$ and $0.01 \mathrm{M} \mathrm{MgCl}_{2}$. After clarification by bentonite solution (35), the virus was precipitated by $8 \%$ polyethylene glycol 6000. The pellet was then suspended in $15 \mathrm{ml}$ of $0.05 \mathrm{M}$ Tris-HCl (pH 7.2) and used for inoculation. Two grams of GINVinfected C. quinoa and ASPV-infected N. occidentalis leaves were homogenized in $10 \mathrm{ml}$ of $0.1 \mathrm{M}$ Tris- $\mathrm{HCl}(\mathrm{pH} \mathrm{7.2)}$ and $0.01 \mathrm{M}$ $\mathrm{MgCl}_{2}$, and the homogenates were used for inoculation.

$\mathrm{R}_{1}$ seedlings of transgenic $N$. occidentalis plants were grown to the six- to seven-leaf stage in pots. Only seedlings expressing P50 or $\mathrm{CP}$ were used for virus inoculation. Three leaves per plant were mechanically inoculated with each virus. Five to nine plants per transgenic line were assayed in each infection test, and all experiments were repeated twice. Inoculated plants were grown in a growth chamber for symptom observation.

Analyses of inoculated plants. Inoculated and uninoculated upper leaves were collected several times from $N$. occidentalis plants inoculated with each virus, and the virus accumulations were assayed as follows. For ACLSV, leaves were ground with 0.01 M Tris$\mathrm{HCl}(\mathrm{pH} 7.2)$ and $0.01 \mathrm{M} \mathrm{MgCl}_{2}$ (4 ml/g of leaves) with a mortar and pestle, and the extracts were inoculated mechanically to four leaves of a $C$. quinoa plant (eight- to nine-leaf stage, three plants per sample). The number of lesions on inoculated leaves was counted 5 days after inoculation.

GINV, ASGV, and ASPV were assayed by indirect enzyme-linked immunosorbent assay (ELISA) using antisera against each virus (15). Leaves $(0.1 \mathrm{~g})$ were ground with $2.5 \mathrm{ml}$ of $0.05 \mathrm{M}$ carbonate

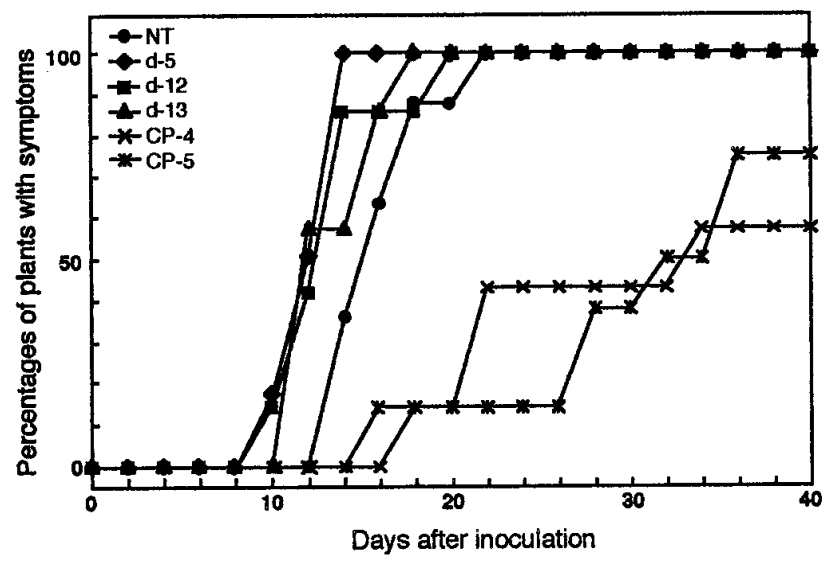

Fig. 3. Time course of symptom development in upper leaves of nontransgenic (NT) and transgenic Nicotiana occidentalis expressing Apple chlorotic leaf spot virus (ACLSV) 50-kDa protein (lines d-5, d-12, and d-13) or coat protein (lines CP-4 and CP-5) inoculated with ACLSV infectious cDNA clone (pCLSF) by particle bombardment. Eight plants per line were used in the experiment. buffer ( $\mathrm{pH}$ 9.6), followed by centrifugation for $10 \mathrm{~min}$ at $15,000 \times \mathrm{g}$. Antisera that had been cross-absorbed against healthy $N$. occidentalis sap were used at a dilution of $1 / 2,000$. Anti-rabbit immunoglobulin $\mathrm{G}$ conjugated with alkaline phosphatase (Tagoimmunologicals, Camarillo, CA) was used as a second antibody at a dilution of $1 / 2,000$.

For northern blot analysis, negative-stranded RNA probes were prepared from a cDNA clone of each virus using a digoxigenin RNA labeling kit (Boehringer Mannheim, Tokyo). The nt positions of the RNA probes were 21 to 2,062 for ACLSV (P-205) (24), 825 to 2,469 for GINV (32), 5,138 to 6,496 for ASGV (P-209) (34), and 6,181 to 7,421 for ASPV (N. Yoshikawa, unpublished data). Total RNA was extracted from inoculated $N$. occidentalis leaves $(0.1 \mathrm{~g})$ according to Verwoerd et al. (30), electrophoresed in $1 \%$ agarose gel containing formaldehyde (23), and transferred to a Hybond-N membrane (Amersham, Tokyo). Prehybridization, hybridization, and chemiluminescent detection were conducted according to the protocols supplied by Boehringer Mannheim.

\section{RESULTS}

Expression of ACLSV P50 and CP in transgenic plants. Among regenerated plants from the tissues transformed with pBE2113-50K or pBE2113-CP, we selected three P50-expressing $N$. occidentalis plant lines (d-5, d-12, and d-13) and two CP-expressing lines (CP-4 and $\mathrm{CP}-5$ ). Seedlings from the $\mathrm{R}_{1}$ generation segregated 3:1 for resistance to kanamycin. Immunoblot analysis showed that P50 and CP were expressed in all samples from kanamycin-resistant $\mathrm{R}_{1}$ seedlings of each line (Fig. 2), confirming the 3:1 segregation of these genes. No differences in the amount of the expressed proteins were noted among the three lines ex-
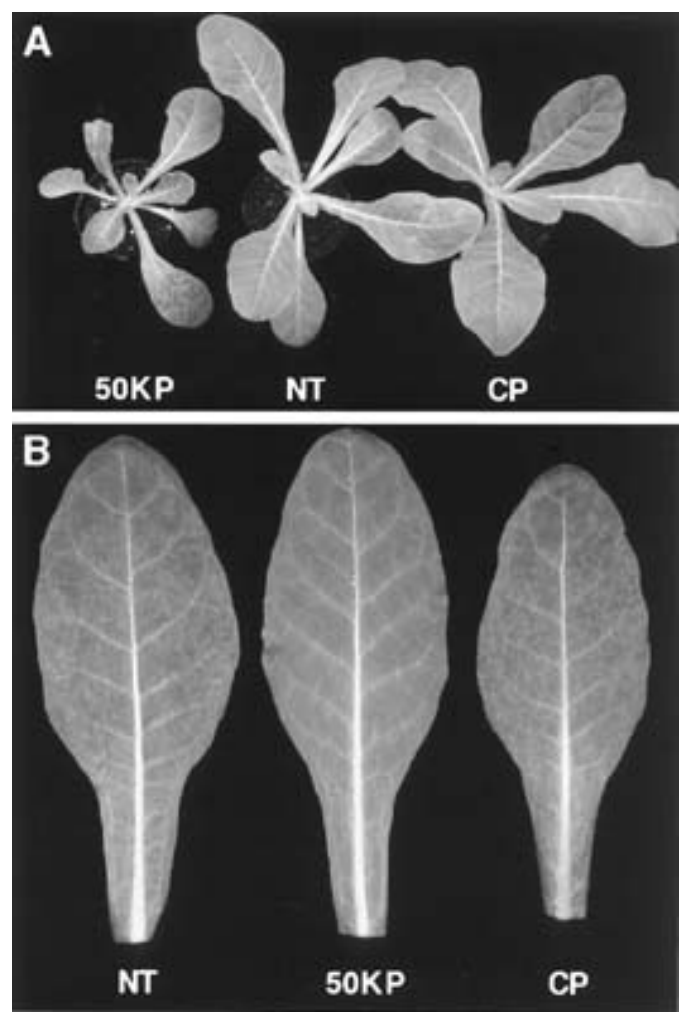

Fig. 4. A, Severe symptoms (dwarfing and distortion) of transgenic Nicotiana occidentalis plants expressing Apple chlorotic leaf spot virus (ACLSV) $50-\mathrm{kDa}$ protein (P50) compared with nontransgenic (NT)- and coat protein (CP)-expressing plants inoculated with ACLSV infectious cDNA clone pCLSF by particle bombardment. B, Leaf symptoms of NT, P50, and CP plants mechanically inoculated with Grapevine berry inner necrosis virus. Note chlorotic spots on whole leaves of NT and CP plants, but not on the leaf from the P50 plant. 
pressing P50 (d-5, d-12, and d-13) or between the two lines expressing $\mathrm{CP}$ (CP-4 and $\mathrm{CP}-5)$.

Total proteins from leaf samples of d-5 plants at three leaf stages (YL, DL, and ML) were analyzed by immunoblotting. In YL, P50 was detected as two bands of approximately 50 and $52 \mathrm{kDa}$ (data not shown). The $52-\mathrm{kDa}$ band was thought to be a posttranslationally modified (phosphorylated) protein, the same as the 52-kDa protein previously reported to be found in ACLSV-infected C. quinoa leaves (25). The posttranslational modification of the 50-kDa protein seemed to be correlated with leaf maturation, i.e., in mature leaves; the modified 52-kDa protein was dominant.

To examine the subcellular location of P50 in transgenic plant leaves, subcellular extracts prepared from YL, DL, and ML of the d-5 line were analyzed by immunoblotting. In YL, P50 was detected in all subcellular fractions, i.e., CW, CW-T, P-30, and S-30 fractions. On the other hand, P50 was predominantly distributed in the CW fraction in DL and ML (data not shown).

Complementation of ACLSV P50-defective mutants in transgenic plants expressing P50. pStuStop was designed to express only the N-terminal 35 amino acids of P50, and p $\Delta$ StuNhe was designed to synthesize an incomplete P50 (Fig. 1A). When pStuStop or $\mathrm{p} \Delta$ StuNhe was inoculated onto nontransgenic plants (NT plants) by particle bombardment, no symptoms were observed and viral RNA was not detected in either inoculated leaves or upper uninoculated leaves by northern blot analysis (Fig. 1B). In contrast, transgenic plants expressing P50 (P50 plants) inoculated with pStuStop or $\mathrm{p} \Delta \mathrm{StuNhe}$ showed chlorotic spots on inoculated and uninoculated upper leaves 10 to 14 days postinoculation (dpi) and 18 to $20 \mathrm{dpi}$, respectively. As compared with P50 plants inoculated with pCLSF, symptoms produced by P50-defective mutants were milder and were delayed 2 to 4 days in inoculated leaves and 6 to 8 days in upper leaves. When extracts of leaves from the plants inoculated with defective mutants were inoculated to $C$. quinoa, no symptoms appeared on either inoculated or upper leaves, indicating that wildtype virus was not formed by recombination between the transgene and the P50-defective mutants. Northern blot analysis showed that defective viral RNAs from pStuStop or $\mathrm{p} \Delta$ StuNhe replicated in both inoculated and upper leaves of the three P50 lines (Fig. 1B).

TABLE 1. Responses of transgenic Nicotiana occidentalis plants expressing 50-kDa protein (P50) or coat protein (CP) of Apple chlorotic leaf spot virus (ACLSV) against inoculations by ACLSV, Grapevine berry inner necrosis virus (GINV), Apple stem grooving virus (ASGV), or Apple stem pitting virus (ASPV)

\begin{tabular}{|c|c|c|c|}
\hline Virus & Plant & (Line) & $\begin{array}{l}\text { No. of plants with symptoms } \\
\text { per inoculated plants }\end{array}$ \\
\hline \multirow[t]{6}{*}{ ACLSV } & Nontransgenic (NT) & & $12 / 13$ \\
\hline & P50 & $(d-5)$ & $10 / 10$ \\
\hline & & $(\mathrm{d}-12)$ & $10 / 10$ \\
\hline & & $(d-13)$ & $12 / 12$ \\
\hline & $\mathrm{CP}$ & (CP-4) & $0 / 10$ \\
\hline & & (CP-5) & $2 / 10$ \\
\hline \multirow[t]{6}{*}{ GINV } & NT & & $18 / 18$ \\
\hline & P50 & $(d-5)$ & $0 / 10$ \\
\hline & & $(d-12)$ & $1 / 11$ \\
\hline & & (d-13) & $0 / 11$ \\
\hline & $\mathrm{CP}$ & (CP-4) & $11 / 11$ \\
\hline & & (CP-5) & $10 / 10$ \\
\hline \multirow[t]{6}{*}{ ASGV } & NT & & $0 / 10^{\mathrm{b}}$ \\
\hline & P50 & $(d-5)$ & $0 / 10$ \\
\hline & & $(d-12)$ & $0 / 10$ \\
\hline & & (d-13) & $0 / 10$ \\
\hline & $\mathrm{CP}$ & (CP-4) & $0 / 10$ \\
\hline & & (CP-5) & $0 / 10$ \\
\hline \multirow[t]{6}{*}{ ASPV } & NT & & $16 / 16$ \\
\hline & P50 & $(d-5)$ & $12 / 12$ \\
\hline & & $(\mathrm{d}-12)$ & $12 / 12$ \\
\hline & & (d-13) & $12 / 12$ \\
\hline & $\mathrm{CP}$ & (CP-4) & $12 / 12$ \\
\hline & & (CP-5) & $12 / 12$ \\
\hline
\end{tabular}

${ }^{a}$ Results are the sum of two independent experiments with each virus.

${ }^{b}$ ASGV infected all NT, P50, and CP plants symptomlessly.
Increased susceptibility of the transgenic plants expressing P50 to the inoculation of an ACLSV infectious cDNA clone. Nontransgenic and transgenic $N$. occidentalis seedlings were first inoculated with pCLSF by particle bombardment. Both NT and P50 plants developed chlorotic spots on inoculated leaves 8 to $10 \mathrm{dpi}$. However, clear differences in the appearance and intensity of symptoms were found on uninoculated upper leaves between these plants. In NT plants, chlorotic spots started to appear on upper leaves from 14 dpi (Fig. 3) and symptoms consisted of chlorotic spots on limited areas of leaves or on whole leaves (Fig. 4A). By contrast, chlorotic spots initially appeared on upper leaves 10 to $12 \mathrm{dpi}$ in P50 plants (Fig. 3). Thereafter, mosaic and necrosis developed on leaves and the plants were severely stunted (Fig. 4A). All
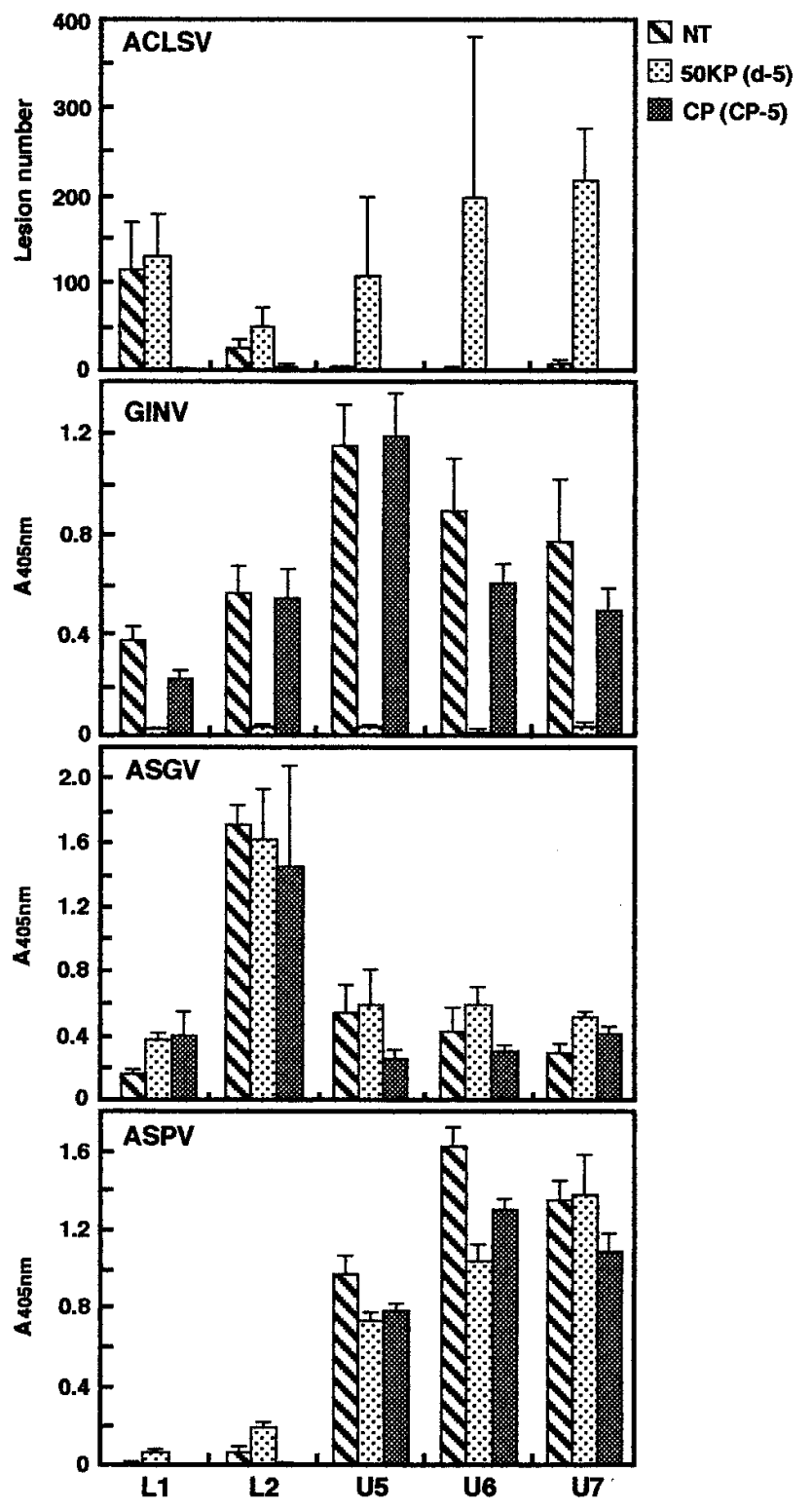

Fig. 5. Virus accumulation in transgenic and nontransgenic Nicotiana occidentalis plants inoculated with Apple chlorotic leaf spot virus (ACLSV), Grapevine berry inner necrosis virus (GINV), Apple stem grooving virus (ASGV), or Apple stem pitting virus (ASPV). Inoculated leaves, L1 and L2, were collected at 1 and 2 weeks after inoculation, respectively, and U5, U6, and U7, the 5th, 6th and 7th upper leaves (numbered from the inoculated leaf), respectively, were collected at 4 weeks after inoculation. ACLSV accumulation was shown by the number of lesions on inoculated leaves of Chenopodium quinoa plants. The concentrations of GINV, ASGV, and ASPV (shown as $A_{405 \mathrm{~nm}}$ values) were determined by enzyme-linked immunosorbent assays. The values represent the mean of five plants per line, and standard deviations are shown by vertical bars. 
three lines (d-5, d-12, and d-13) of P50 plants developed similar severe symptoms.

Transgenic plants expressing $\mathrm{CP}$ (CP plants) inoculated with pCLSF did not develop symptoms on inoculated leaves. Compared with NT plants, there was a 2- to 4-day delay in the appearance of symptoms in upper leaves (Fig. 3) and only 55 to $75 \%$ of the plants developed chlorotic spots on small, limited areas of upper leaves even after 40 dpi (Fig. 3). The experiment was repeated two times and the results were essentially identical.

Response of the transgenic plants expressing P50 to ACLSV, GINV, ASGV, and ASPV infection. Transgenic N. occidentalis plants were mechanically inoculated with ACLSV, GINV, ASGV, or ASPV, and the appearance and intensity of symptoms were compared with NT plants inoculated with the same viruses.

Transgenic and NT plants mechanically inoculated with ACLSV showed almost similar responses to the corresponding plants inoculated with pCLSF by particle bombardment. The P50 plants developed severe leaf symptoms consisting of chlorotic spots, mosaic, necrosis, and malformation. In contrast, NT plants showed only chlorotic spots on limited areas of a few leaves. All CP-5 plants did not show obvious symptoms, and only $20 \%$ of the CP-4 plants showed some chlorotic spots on leaves (Table 1).

Inoculated leaves ( 1 and 2 weeks after inoculation) and upper leaves (4 weeks after inoculation) were collected from NT, P50 (lines d-5, d-12, and d-13), and CP (lines CP-4 and CP-5) plants inoculated with ACLSV, and virus accumulation was assayed by inoculation to $C$. quinoa. In samples of inoculated leaves, there was no difference in lesion number between NT and P50 plants (Fig. 5). In contrast, virus accumulation in upper leaves of P50 plants was strikingly enhanced compared with that in NT plants (Fig. 5). Similar enhanced accumulation of virus in P50 plants was verified by ELISA using ACLSV antiserum (data not shown). Virus accumulation in CP plants, however, was greatly reduced in both inoculated and upper leaves (Fig. 5).

We previously reported that $N$. occidentalis plants infected with GINV showed vein clearing, chlorotic spots, and mosaic in the upper leaves, similar to the symptoms of ACLSV infection (32). In the current study, both NT and CP plants initially developed chlorotic spots and chlorotic ringspots on upper leaves 14 dpi (Fig. 6). Thereafter, mosaic symptoms appeared on whole leaves (Fig. 4B). Unexpectedly, most P50 plants did not develop obvious symptoms on either inoculated or upper leaves in all three lines (Figs. 4B and 6). Of the 32 plants inoculated with GINV, only one plant of line d-12 showed leaf symptoms (Table 1). ELISA assay showed that virus accumulated in the inoculated and upper leaves of both NT and CP plants, but not in P50 plants (Fig. 5). GINV RNA was also not detected in leaves of the P50 plants (data not shown).

ASGV can infect $N$. occidentalis plants symptomlessly. Neither P50 nor CP plants developed any symptoms following ASGV inoculation (Table 1), and no differences in virus accumulation were found among NT, P50, and CP plants, as indicated by ELISA (Fig. 5) and northern hybridization (data not shown).

All NT, P50, and CP plants inoculated with ASPV developed chlorotic and necrotic spots on inoculated leaves 5 to 6 dpi and mosaic, necrosis, and malformation on upper leaves 10 to $12 \mathrm{dpi}$ (Table 1). There were no differences in the intensity of symptoms and virus accumulation in both inoculated and upper leaves among NT, P50, and CP plants (Fig. 5).

\section{DISCUSSION}

We previously reported that ACLSV P50 is detected in cell wall and cell membrane fractions as protein of a molecular mass of $52 \mathrm{kDa}$, larger than full-length $(50 \mathrm{kDa})$ protein expressed in E. coli $(25)$, and localized on plasmodesmata and nearby cytoplasm in infected C. quinoa leaves (33). Immunoblot analyses reported here showed that the protein is mainly detected in the cell wall fraction in a modified form, similar to that in infected $C$. quinoa plants. Fur- thermore, the P50-transgenic plants can complement the systemic spread of the P50-defective mutants of ACLSV. These results indicate that P50 in transgenic plants is functional and can complement the cell-to-cell and systemic movement of the P50-defective mutants, as reported in MPs of other viruses $(12,14)$.

The P50 plants were more susceptible to ACLSV and, conversely, the $\mathrm{CP}$-transgenic plants were resistant to this virus. The increased susceptibility of the P50 plants is similar to the report that transgenic N. tabacum 'Xanthi NN' expressing a functional TMV P30 increased the size of lesions compared with nontransgenic tobacco after inoculation of TMV (6). The increased susceptibility of the P50 plants to ACLSV is caused by the accelerated systemic movement of virus from inoculated leaves to upper uninoculated leaves in the P50 plants, because no difference in virus accumulation was found in inoculated leaves between P50 and NT plants. We recently reported that P50 fused to enhanced green fluorescent protein accumulates in sieve elements, in addition to the localization in plasmodesmata in leaves of transgenic plants (33). P50 expressed in transgenic plants may facilitate the long-distance movement of the viral genome through sieve elements and allow efficient movement between bundle sheath and phloem in leaf veins, which is a boundary for the systemic movement of viruses (28).

We initially expected that the P50 plants might increase susceptibility to GINV, ASGV, and ASPV infection, as in the case of TMV P30-transgenic tobacco plants (14). However, the P50 plants showed strong resistance to GINV in both inoculated and uninoculated upper leaves. This resistance is virus specific, because there were no differences in responses among P50, CP, and NT plants against ASGV or ASPV infection. As GINV is classified in the genus Trichovirus (32) and is phylogenetically closer to ACLSV than to ASGV and ASPV, this specificity may be due to the similarity of functional domains in MPs between ACLSV and GINV. Amino acid sequence identities of MPs are $36 \%$ between ACLSV and GINV and $25 \%$ between ACLSV and ASGV (32). Ares et al. (1) described a model to explain the resistance to tobamoviruses in tobacco expressing a functional P24 encoded by PVX-TGB. According to this model, MPs of ACLSV and GINV may have multiple functional domains, those performing equivalent activities and those specific to each virus protein, and the P50 expressed in transgenic plants may act as a competitor for a limiting cellular factor associated with the equivalent activity of GINV-MP.

To understand the MP-derived resistance reported here, studies are underway to examine which region(s) of P50 is involved in the resistance to GINV and to determine whether plants expressing GINV-MP also show resistance to ACLSV.

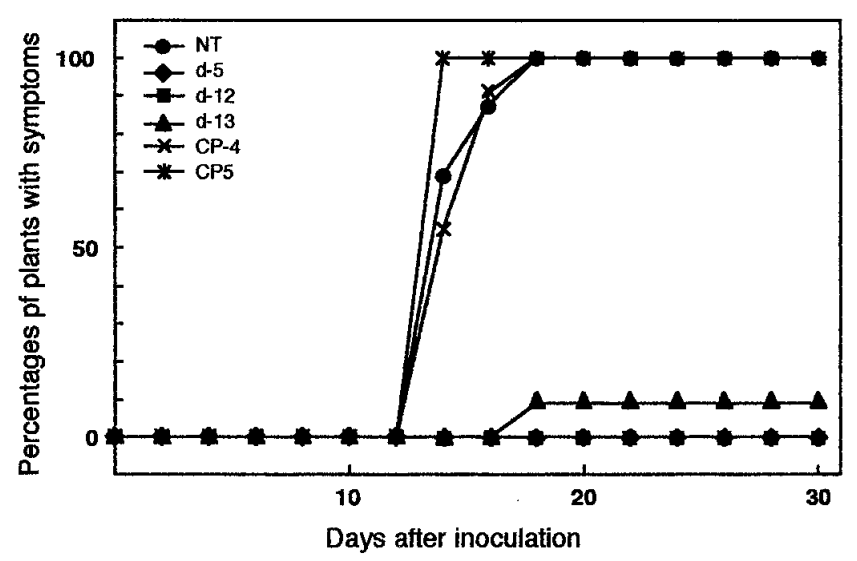

Fig. 6. Time course of symptom development (chlorotic spots and mosaic) in nontransgenic (NT) and transgenic Nicotiana occidentalis expressing Apple chlorotic leaf spot virus $50-\mathrm{kDa}$ protein (lines d-5, d-12, and d-13) or coat protein (lines CP-4 and CP-5) mechanically inoculated with Grapevine berry inner necrosis virus. Five to nine plants per line were used in the experiment. 


\section{ACKNOWLEDGMENTS}

We thank Y. Ohashi for providing pBE2113-GUS and S. Nakamura for helpful technical advice. We also thank R. H. Converse (USDA-ARS) for his critical reading of the manuscript.

\section{LITERATURE CITED}

1. Ares, X., Calamante, G., Cabral, S., Lodge, J., Hemenway, P., Beachy, R. N., and Mentaberry, A. 1998. Transgenic plants expressing potato virus $\mathrm{X}$ ORF2 protein (p24) are resistant to tobacco mosaic virus and Ob tobamoviruses. J. Virol. 72:731-738.

2. Atkins, D., Hull, R., Wells, B., Roberts, K., Moore, P., and Beachy, R. N. 1991. The tobacco mosaic virus 30K movement protein in transgenic tobacco plants is localized to plasmodesmata. J. Gen. Virol. 72:209-211.

3. Beck, D. L., van Dolleweerd, C. J., Lough, T. J., Balmori, E., Voot, D. M., Andersen, M. T., O'Brien, I. E. W., and Forster, R. L. S. 1994. Disruption of virus movement confers broad-spectrum resistance against systemic infection by plant viruses with a triple gene block. Proc. Natl. Acad. Sci. U.S.A. 91:10310-10314

4. Carrington, J. C., Kasschau, K. D., Mahajan, S. K., and Schaad, M. C. 1996. Cell-to-cell and long-distance transport of viruses in plants. Plant Cell 8:1669-1681.

5. Citovsky, V., Knorr, D., Schuster, G., and Zambryski, P. 1990. The P30 movement protein of tobacco mosaic virus is a single-strand nucleic acid binding protein. Cell 60:637-647.

6. Cooper, B., Lapidot, M., Heick, J. S., Dodds, J. A., and Beachy, R. N. 1995. A defective movement protein of TMV in transgenic plants confers resistance to multiple viruses whereas the functional analog increase susceptibility. Virology 206:307-313.

7. Deom, C. M., Schubert, K. R., Wolf, S., Holt, C. A., Lucas, W. J., and Beachy, R. N. 1990. Molecular characterization and biological function of the movement protein of tobacco mosaic virus in transgenic plants. Proc. Natl. Acad. Sci. U.S.A. 87:3284-3288.

8. Ding, B., Haudenshield, J. S., Hull, R. J., Wolf, S., Beachy, R. N., and Lucas, W. J. 1992. Secondary plasmodesmata are specific sites of localization of the tobacco mosaic virus movement protein in transgenic tobacco plants. Plant Cell 4:915-928.

9. Fujiwara, T., Giesman-Cookmeyer, D., Ding, B., Lommel, S. A., and Lucas, W. J. 1993. Cell-to-cell trafficking of macromolecules through plasmodesmata potentiated by the red clover necrotic mosaic virus movement protein. Plant Cell 5:1783-1794

10. German, S., Candresse, T., Lanneau, M., Huet, J. C., Pernollet, J. C., and Dunez, J. 1990. Nucleotide sequence and genome organization of apple chlorotic leaf spot closterovirus. Virology 179:104-112.

11. German-Retana, S., Bergey, B., Delbos, R. P., Candresse, T., and Dunez, J. 1997. Complete nucleotide sequence of the genome of a severe cherry isolate of apple chlorotic leaf spot trichovirus (ACLSV). Arch. Virol. 142: 833-841.

12. Holt, C. A., and Beachy, R. N. 1991. In vivo complementation of infectious transcripts from mutant tobacco mosaic virus cDNAs in transgenic plants. Virology 181:109-117.

13. Horsch, R. B., Fry, J. E., Hoffmann, N. L., Eichholtz, D., Rogers, S. G., and Fraley, R. T. 1985. A simple and general method for transferring genes into plants. Science 227:1229-1231.

14. Kaplan, I. B., Shintaku, M. H., Li, Q., Zhang, L., Marsh, L., and Palukaitis, P. 1995. Complementation of virus movement in transgenic tobacco expressing the cucumber mosaic virus 3a gene. Virology 209:188-199.

15. Koenig, R. 1981. Indirect ELISA methods for the broad specificity detection of plant viruses. J. Gen. Virol. 55:53-62.

16. Koganezawa, H., and Yanase, H. 1990. A new type of elongated virus isolated from apple trees containing the stem pitting agent. Plant Dis. 74:610-614.
17. Koonin, E. V., and Doija, V. V. 1993. Evolution and taxonomy of positive-strand RNA viruses: Implications of comparative analysis of amino acid sequences. Crit. Rev. Biochem. Mol. Biol. 28:375-430.

18. Kormelink, R., Storms, M., van Lent, J., Peters, D., and Goldbach, R. 1994 Expression and subcellular location of the $\mathrm{NS}_{\mathrm{M}}$ protein of tomato spotted wilt virus (TSWV), a putative viral movement protein. Virology 200:56-65.

19. Linstead, P. J., Hills, G. J., Plaskitt, A., Wilson, I. G., Harker, C. L., and Maule, A. J. 1988. The subcellular location of the gene 1 product of cauliflower mosaic virus is consistent with a function associated with virus spread. J. Gen. Virol. 69:1809-1818.

20. Lucas, W. J., and Gilbertson, R. L. 1994. Plasmodesmata in relation to viral movement within leaf tissues. Annu. Rev. Phytopathol. 32:387-411.

21. Malyshenko, S. I., Kondakova, O. A., Nazarova, J. V., Kaplan, I. B., Taliansky, M. E., and Atabekov, J. G. 1993. Reduction of tobacco mosaic virus accumulation in transgenic plants producing non-functional viral transport proteins. J. Gen. Virol. 74:1149-1156.

22. Mitsuhara, I., Ugaki, M., Hirochika, H., Oshima, M., Murakami, T., Gotoh, Y., Katayose, Y., Nakamura, S., Honkura, R., Nishimiya, S., Ueno, K., Mochizuki, A., Tanimoto, H., Tsugawa, H., Otsuki, Y., and Ohashi, Y. 1996. Efficient promoter cassettes for enhanced expression of foreign genes in dicotyledonous and monocotyledonous plants. Plant Cell Physiol. 37:49-59.

23. Sambrook, J., Fritsch, E. F., and Maniatis, T. 1989. Molecular Cloning: A Laboratory Manual, 2nd ed. Cold Spring Harbor Laboratory, Cold Spring Harbor, NY.

24. Sato, K., Yoshikawa, N., and Takahashi, T. 1993. Complete nucleotide sequence of the genome of an apple isolate of apple chlorotic leaf spot virus. J. Gen. Virol. 74:1927-1931.

25. Sato, K., Yoshikawa, N., Takahashi, T., and Taira, H. 1995. Expression subcellular location and modification of the $50 \mathrm{kDa}$ protein encoded by ORF2 of the apple chlorotic leaf spot trichovirus genome. J. Gen. Virol. 76:1503-1507.

26. Satoh, H., Yoshikawa, N., and Takahashi, T. 1999. Construction and biolistic inoculation of an infectious cDNA clone of apple chlorotic leaf spot trichovirus. Ann. Phytopathol. Soc. Jpn. 65:301-304.

27. Seppänen, P., Puska, R., Honkanen, J., Tyulkina, L. G., Fedorkin, O., Morozov, S. Yu., and Atabekov, J. G. 1997. Movement protein-derived resistance to triple gene block-containing plant viruses. J. Gen. Virol. 78: 1241-1246.

28. Thompson, J. R., and García-Arenal, F. 1998. The bundle sheath-phloem interface of Cucumis sativus is a boundary to systemic infection by tomato aspermy virus. Mol. Plant-Microbe Interact. 11:109-114.

29. Tomenius, K., Clapham, D., and Meshi, T. 1987. Localization by immunogold cytochemistry of the virus-coded $30 \mathrm{~K}$ protein in plasmodesmata of leaves infected with tobacco mosaic virus. Virology 160:363-371.

30. Verwoerd, T. C., Dekker, B. M. M., and Hoekema, A. 1989. A smallscale procedure for the rapid isolation of plant RNAs. Nucleic Acids Res. 17:2362.

31. Wolf, S., Deom, C. M., Beachy, R. N., and Lucas, W. J. 1989. Movement protein of tobacco mosaic virus modifies plasmodesmatal size exclusion limit. Science 246:377-379.

32. Yoshikawa, N., Iida, H., Goto, S., Magome, H., Takahashi, T., and Terai, Y. 1997. Grapevine berry inner necrosis, a new trichovirus: Comparative studies with several known trichoviruses. Arch. Virol. 142:1351-1363.

33. Yoshikawa, N., Oogake, S., Terada, M., Miyabayashi, S., Ikeda, Y., Takahashi, T., and Ogawa, K. 1999. Apple chlorotic leaf spot virus $50 \mathrm{kDa}$ protein is targeted to plasmodesmata and accumulated in sieve elements in transgenic plant leaves. Arch. Virol. 144:2475-2483.

34. Yoshikawa, N., Sasaki, E., Kato, M., and Takahashi, T. 1992. The nucleotide sequence of apple stem grooving capillovirus genome. Virology 191:98-105.

35. Yoshikawa, N., and Takahashi, T. 1988. Properties of RNAs and proteins of apple stem grooving and apple chlorotic leaf spot viruses. J. Gen. Virol. 69:241-245. 